\title{
ГОСУДАРСТВЕННАЯ И МУНИЦИПАЛЬНАЯ ПОДДЕРЖКА МАЛОГО ПРЕДПРИНИМАТЕЛЬСТВА Г. СТАВРОПОЛЯ: ИНСТРУМЕНТЫ РЕАЛИЗАЦИИ
}

Автором рассмотрена актуальная система поддержки субъектов малого предпринимательства города Ставрополя. Проанализирован основной инструментарий государственюй и муниципальной поддержки субъектов малого бизнеса в городе, сделан вывод о соответствии инструментария федеральному законодательству о поддерюкке субъектов малого и среднего предпринимательства. Анализ суиествующего инструментария поддержки малого и среднего предпринимательства особенно актуален после изменений федерального законодательства о поддержке малого и среднего предпринимательства, в частности - федерального закона «О развитии малого и среднего предпринимательства в Российской Федерации». При этом важньм является анализ успеиности приведения местного законодательства в соответствие с федеральным законодательством. Выделены наиболее перспективные инструменты поддержск малого предпринимательства в муниципальном образовании.

Ключевые слова: предпринимательство, малый бизнес, государственная поддержка, субъекты предпринимательства.

Alexander Ryadchin

\section{STATE AND MUNICIPAL SUPPORT OF SMALL BUSINESS IN STAVROPOL: INSTRUMENTS OF IMPLEMENTATION}

The author considered the relevant system of support of small business entities of the city of Stavropol. The main tools of the state and municipal support of subjects of small business in the city are analysed, the conclusion is drawn on compliance of tools to the federal legislation on support of subjects of small and average business. The analysis of the existing tools of support of small and average business is especially relevant after changes of the federal legislation on support of small and average business, in particular-the federal law from "On development of small and average business in the Russian Federation". At the same time the analysis success of reduction of the local legislation in compliance with the legislation federal is important. The most perspective instruments of support of small business in municipal unit are allocated.

Key words: business, small business, state support, subjects of business.

Bведение / Introduction. Поиск новых путей и форм поддержки малого предпринимательства, к которому действующим законодательством отнесены микропредприятия и индивидуальные предприниматели, весьма актуален в настоящее время. Свидетельствует об этом, например, поиск государственными органами новых подходов к работе с субъектами малого предпринимательства. Так, например, федеральная налоговая служба в октябре 2018 года представила законопроект, согласно которому отдельные субъекты малого бизнеса, если их доход в год не превышает 2,4 млн рублей и они не нанимают работников, могут платить общий налог в $4 \%$, что значительно ниже всех других налоговых систем, реализующихся в настоящее время при налогообложении субъектов малого бизнеса. Развитый бизнес предоставляет государству множество возможностей: и поступление от налогов в бюджеты разных уровней власти, и создание и обеспечение населения рабочими местами, выплата за работников взносов во внебюджетные фонды, поддержание конкуренции на рынке и расширение перечня предоставляемых товаров и услуг. Нельзя недооценивать и то, что развитое предпринимательство поддерживает политическую стабильность в обществе, в чем так нуждается современная Россия. Именно поэтому анализ и выявление наиболее перспективных инструментов поддержки малого предпринимательства так актуален в настоящее время. 
Maтериалы и методы / Materials and methods. Объектом данного исследования является малое предпринимательство города Ставрополя. Предметом исследования выступает система управленческих, организационно-правовых и экономических форм государственной поддержки субъъектов малого предпринимательства в г. Ставрополе. Проведенные исследования базируются на абстрактно-логическом методе, системном подходе и системном анализе как общенаучных методах познания.

Информационную базу исследования составили: федеральное законодательство о поддержке и развитии малого предпринимательства, целевые программы поддержки малого предпринимательства Ставропольского края и г. Ставрополя, научные статьи.

Государственная и муниципальная поддержка субъектов малого предпринимательства в г. Ставрополе осуществляется на основании федерального закона «О развитии малого и среднего предпринимательства в Российской Федерации» [5] и подпрограммы «Развитие малого и среднего предпринимательства в городе Ставрополе» муниципальной программы «Экономическое развитие города Ставрополя» [1].

При характеристике государственной и муниципальной поддержки малого предпринимательства в г. Ставрополе необходимо учитывать различия в полномочиях органов власти всех уровней. Важно также сказать, что органы местного самоуправления более ограничены в своих полномочиях, нежели органы государственной власти, так как именно на федеральном уровне посредством принятия федеральных законов, регулирующих данную сферу, закладываются основные принципы и направления, которым должны следовать органы местного самоуправления. Иначе говоря, органы местного самоуправления изначально поставлены в определенные «рамки», устанавливающие границы тех допустимых действий, которые органы местного самоуправления могут реализовывать с целью поддержки и развития субъектов малого предпринимательства в своих муниципальных образованиях.

Полномочия органов местного самоуправления города Ставрополя относительно поддержки и развития малого предпринимательства хотя и ограничены рамками федерального законодательства, но все же обширны по своему содержанию. Так, к основным полномочиям органа местного самоуправления города Ставрополя по поддержке и развитию субъектов малого предпринимательства относятся: создание и дальнейшая реализация муниципальных программ по поддержке малого предпринимательства; формирование инфраструктуры поддержки малого предпринимательства на своей территории с учетом требований федерального законодательства.

Федеральным законодательством о развитии малого и среднего предпринимательства с поправками на 3 августа 2018 года предусмотрены 4 вида поддержки малого предпринимательства: финансовая, имущественная, информационная, консультационная [5]. В городе Ставрополе местными органами власти и государственными органами Ставропольского края реализуются все названные в законе формы, инструменты поддержки предпринимательства.

Говоря об опыте государственной и муниципальной поддержки малого предпринимательства в г. Ставрополе, нельзя не уделить внимания системе сложившихся программ, направленных на поддержание и развитие субъектов предпринимательства.

Так, до 2016 года в г. Ставрополе действовала программа по поддержке предпринимательства «Развитие малого и среднего предпринимательства в городе Ставрополе» [3]. В настоящее время на территории г. Ставрополя реализуется подпрограмма «Развитие малого и среднего предпринимательства в городе Ставрополе» программы [2]. Действующая программа, что довольно необычно, рассчитана на более длительный срок реализации - с 2017 года по 2022 год, что необычно еше и потому, что традиционно подобные программы в субъектах Российской Федерации действуют не более трех лет. В качестве примера здесь можно привести программы поддержки малого и среднего предпринимательства, действующие в г. Ставрополе в последние 10 лет. 
Данная подпрограмма по поддержке малого и среднего предпринимательства осуществляется за счет собственных средств бюджета города Ставрополя. На реализацию данной программы, ее ресурсное обеспечение выделено 36435000 рублей.

Руководствуясь данными о ресурсном обеспечении действующей подпрограммы развития малого и среднего предпринимательства и учитывая данные о ресурсном обеспечении подпрограмм предыдущих годов, можно сделать вывод, что поддержка малого и среднего предпринимательства в г. Ставрополе является одним из важнейших направлений развития, которому и органы государственной власти Ставропольского края, и муниципальные органы Ставрополя уделяют особое внимание.

Результаты и обсуждение / Results and discussion. В рамках реализации предыдущих подпрограмм и программ, а именно подпрограммы «Развитие малого и среднего предпринимательства в городе Ставрополе» и программы «Экономическое развитие города Ставрополя на 2014-2018 годы», была оказана информационная и консультационная поддержка более чем 4000 субъектов малого и среднего предпринимательства, которые осуществляли свою деятельность в границах муниципального образования города Ставрополя. Объем же финансовой поддержки за данный период составил в общей сумме 10729680 рублей [2]. Также в прошедшие годы в г. Ставрополе было проведено на безвозмездной основе семь обучающих семинаров, два круглых стола, одна научно-практическая конференция. Эти данные свидетельствуют об активной работе властей региона по поддержке субъектов предпринимательства.

Успешно в городе Ставрополе реализуются и мероприятия по финансовой поддержке субъектов малого предпринимательства. Данный вид финансовой поддержки субъектов малого предпринимательства в г. Ставрополе предполагает предоставление субсидий субъектам малого предпринимательства, которые реализуют свою деятельность в пределах города. Субсидии предоставляются в 2018 году [4]:

1) на возмешение части процентных ставок по привлеченным кредитам на модернизацию существующих производств и открытие новых производств на территории города Ставрополя;

2) финансовое обеспечение затрат, которые связаны с открытием субъьектами малого предпринимательства собственного бизнеса в сфере производства товаров и оказания услуг;

3) частичное возмещение затрат, понесенных субъектами малого предпринимательства города Ставрополя и связанных с подключением объектов капитального строительства производственного назначения к инженерным сетям газоснабжения на территории города Ставрополя.

В структуру государственной поддержки малого предпринимательства г. Ставрополя входит и некоммерческая организация - микрокредитная компания «Фонд микрофинансирования субъектов малого и среднего предпринимательства в Ставропольском крае». Данный фонд обеспечивает доступ представителей малого предпринимательства города Ставрополя к финансовым ресурсам посредством предоставления займов субъектам малого и среднего предпринимательства Ставропольского края. Именно данный фонд располагает наиболее значимым количеством финансовых инструментов поддержки суббъектов малого предпринимательства, чем иные структуры, созданные на территории г. Ставрополя.

Заключение / Conclusion. Таким образом, можно говорить о всесторонней поддержке субъектов малого предпринимательства в г. Ставрополе со стороны как органов муниципальной, так и государственной власти. В городе осуществляются все виды поддержки малого предпринимательства, предусмотренные действующим федеральным законодательством, используются все основные инструменты реализации финансовой, имущественной, консультационной и информационной поддержки субъектов малого бизнеса в муниципальном образовании. Местные власти своевременно изменяют инструментарий поддержки малого и среднего предпринимательства, приводя его в соответствие с федеральным законодательством. 


\section{ЛИТЕРАТУРА И ИНТЕРНЕТ-РЕСУРСЫ}

1. Об утверждении муниципальной программы «Экономическое развитие города Ставрополя на 2014 2016 годы»: Постановление администрации г. Ставрополя от 31.10.2013 № 3834 // СПС «КонсультантПлюс».

2. Об утверждении долгосрочной муниципальной целевой программы «Развитие малого и среднего предпринимательства в городе Ставрополе»: Постановление администрации города Ставрополя от 8 октября 2010 года № 3011 // СПС «КонсультантПлюс».

3. Рядчин А. А. Аналитическая оценка потенциала малого бизнеса Ставропольского края и перспективы его развития // Вестник Северо-Кавказского федерального университета. 2017. № 5. С. 136-143.

4. Рядчин А. А. Анализ и оценка эффективности государственной поддержки малого предпринимательства в г. Ставрополь // Вестник Северо-Кавказского федерального университета. 2018. № 2. C. $138-142$.

5. О развитии малого и среднего предпринимательства в Российской Федерации: Федеральный закон от 24.07.2007 № 209-Ф3 (ред. от 27.11.2017) // СПС «КонсультантПлюс».

\section{REFERENCES AND INTERNET RESOURCES}

1. Ob utverzhdenii municipal'noj programmy «EHkonomicheskoe razvitie goroda Stavropolya na 20142018 gody» (Approval of the municipal program «Economic development of the city of Stavropol for 2014-2016»): Postanovlenie administracii goroda Stavropolya ot 31 oktyabrya 2013 g. N 3834 // SPS «Konsul'tantPlyus».

2. Ob utverzhdenii municipal'noj programmy «Podderzhka subektov malogo i srednego predprinimatel'stva v Stavropole» (About the approval of the long-term municipal target program «Development of small and medium business in the city of Stavropol»): Postanovlenie administracii Stavropolya ot 8 oktyabrya 2010 N 3011 // SPS «Konsul'tantPljus».

3. Ryadchin A. A. Analiticheskaya ocenka potenciala malogo biznesa Stavropol'skogo kraya i perspektivy ego razvitiya (Analytical evaluation of small business opportunities in Stavropol and its development prospects) // Vestnik Severo-Kavkazskogo federal'nogo universiteta. 2017. No. 5. S. 136-143.

4. Rjadchin A. A. Analiz i ocenka jeffektivnosti gosudarstvennoj podderzhki malogo predprinimatel'stva v g. Stavropol' (Analysis and evaluation of the effectiveness of state support of small business in Stavropol) // Vestnik Severo-Kavkazskogo federal'nogo universiteta. 2018. No 2. S. 138-142.

5. O razvitii malogo i srednego predprinimatel'stva v Rossijskoj Federacii (About development of small and average business in the Russian Federation): Federal'nyj zakon ot 24.07.2007 N 209-FZ (red. ot 03.08.2018) (s izm. i dop., vstup. v silu s 01.08.2016) // SPS «Konsul'tantPlyus».

\section{СВЕДЕНИЯ ОБ АВТОРЕ}

Рядчии Александр Александрович, магистрант кафедры государственного и муниципального управления Волгоградского государственного университета (Проспект Университетский, 100, 400062 г. Волгоград, Российская Федерация). E-mail: alexandrrusso@mail.ru

\section{INFORMATION ABOUT AUTHOR}

Aleksandr Ryadchin, Student of department of the public and municipal administration Volgograd State University (Prospekt Universitetskij, 100, 400062 Volgograd, Russian Federation). E-mail: alexandrrusso@mail.ru 